\title{
Interface Bond Characterization between Fiber and Cementitious Matrix
}

\author{
Won-Chang Choi, ${ }^{1}$ Seok-Joon Jang, ${ }^{2}$ and Hyun-Do Yun ${ }^{2}$ \\ ${ }^{1}$ Department of Architectural Engineering, Gachon University, Gyeonggi 13120, Republic of Korea \\ ${ }^{2}$ Department of Architectural Engineering, Chungnam National University, Daejeon 34134, Republic of Korea
}

Correspondence should be addressed to Hyun-Do Yun; wiseroad@cnu.ac.kr

Received 5 June 2015; Revised 11 August 2015; Accepted 11 August 2015

Academic Editor: Osman Gencel

Copyright ( $(2015$ Won-Chang Choi et al. This is an open access article distributed under the Creative Commons Attribution License, which permits unrestricted use, distribution, and reproduction in any medium, provided the original work is properly cited.

\begin{abstract}
The use of high performance composite fibers allows for the improvement of the mechanical properties of cement composites. Previous research results indicate that the mechanical properties of such composites are determined predominantly by the interface properties between the fiber and cementitious matrix. Many researchers have conducted single-fiber pull-out tests using cementitious composites to quantify the interfacial properties between the fiber and cement matrix. This paper aims to establish a design methodology that employs coefficients to represent the design parameters for the interfacial properties for three types of fibers: carbon fiber, polypropylene fiber, and twisted wire strand steel cord. The parameters for each type of fiber include the water-to-binder ratio and fiber embedment length. The adopted equation used for the numerical analysis was calibrated using experimental data, and design coefficients are proposed accordingly. The developed models could be validated successfully, and the pull-out characteristics of each fiber type are presented.
\end{abstract}

\section{Introduction}

Fiber-reinforced cementitious composites (FRCCs) have unique tensile characteristics due to the fiber-bridging action that occurs across fine multiple cracks, which allows for the even distribution of the fibers. These mechanical characteristics result in tensile strain-hardening behavior with a high level of tensile deformation. The bridging action contributes to the composite's toughness by activating the fiber-matrix interface where energy is dissipated through the debonding of the interface and fiber pull-out [1]. The interfacial bond strength can be computed using the nonconstant interfacial shear strength that surrounds the fibers so that the fibermatrix interfacial bond strength, which is a primary factor of the composite's behavior, can possibly be quantified by single-fiber pull-out testing of the cement composites. In the literature, results of single-fiber pull-out tests of cement composites, designed to examine the interfacial behavior of the fiber/cement composite matrix, have been reported [2].
The composite properties of the interface between the fiber and cement matrix have been examined in many studies found in the literature; these properties include composite strength, fatigue, ductility, energy absorption, and interface failure mode [3].

Li $[2,3]$ presented comprehensive research results in terms of the interface property characteristics of cement composites and developed numerical equations. One of Li's developed models is a strength-controlled model that is based on interface bond performance and is adopted in this study. The interface bond is characterized by frictional bonding and chemical bond strength. It is assumed that the debonding zone that incorporates the embedment length of the fiber is propagated when the shear stress overcomes a critical value at the tip of the debonding location [4].

A simplification of this phenomenon is that the pullout load is resisted by a combination of the chemical bond strength and the frictional bond strength, which is not achieved on a robust physical basis but in a phenomenological 


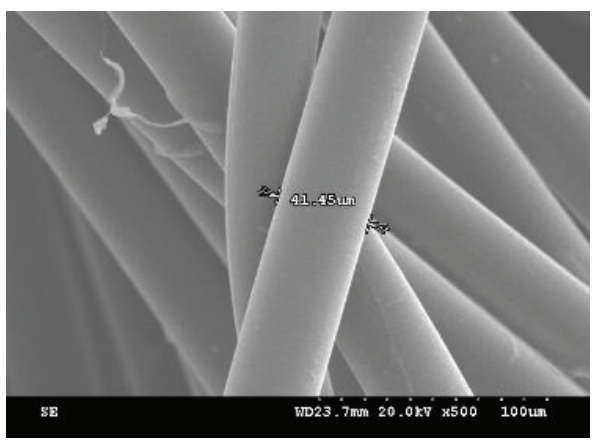

(a) Before fluorination

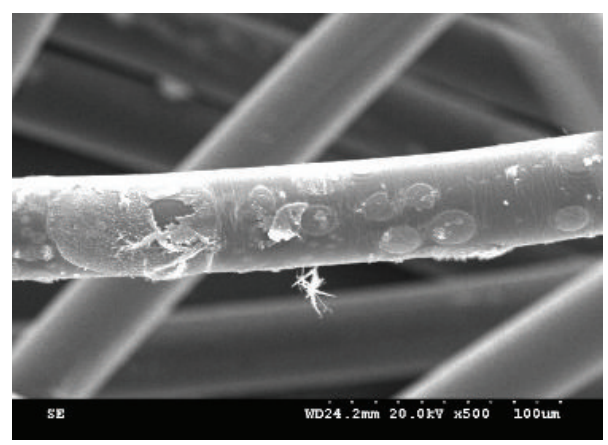

(b) After fluorination

FIGURE 1: SEM images before and after fluorination of polypropylene fiber [9].

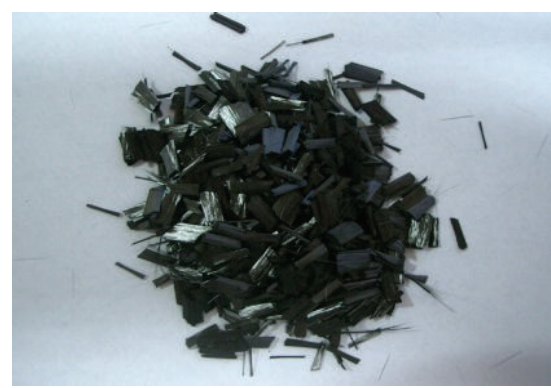

Carbon fiber (C)

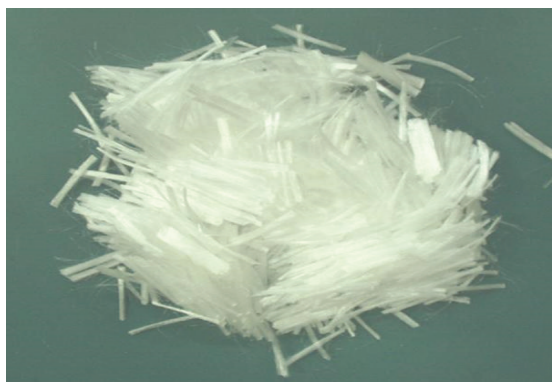

Polypropylene (P)

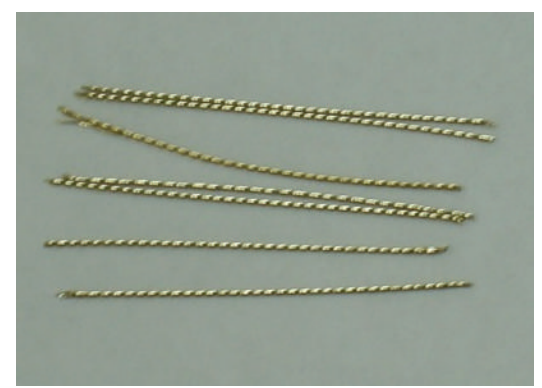

Steel cord (S)

FIGURE 2: Images of composite fibers.

manner. After the transition from the debonding process to the pull-out process, the frictional bond is more dominant than the chemical bond in the pull-out process.

Therefore, in order to enhance the interfacial bond strength between the fiber and the cement composite matrix, various surface treatment techniques have been developed; these include plasma treatment, fiber fibrillation, fiber clamping, fiber twisting, and interface densification, the choice of which depends on the strength and strain capacity of the selected fiber [4]. Likely, many researches have been undertaken to enhance bond strength mechanically and chemically [5-8]. Among these possible surface enhancements, fluorination of carbon fiber and polypropylene fiber was used as a surface treatment in a previous study by the authors [9]. Figure 1 shows the difference in the polypropylene fiber before and after fluorination from scanning electron microscope (SEM) images. After fluorination, the abrupt discontinuity of the pull-out load was prevented after reaching the peak pullout load.

This study is designed to assess the influential interface property characteristics with respect to the water-to-binder ratio of a composite mix, the embedment length of the fibers, and the type of fiber. These experimental results will allow the development of a rational analytical model to describe the bond behavior of FRCCs. For this purpose, an experimental program was carried out, and an adopted analytical model was implemented to obtain the design parameters.

\section{Experimental Program}

To investigate the pull-out mechanisms, both experimental research and theoretical research into single-fiber pull-out in a cementitious composite were undertaken in this study. Experimental testing was designed for three types of fiber (carbon fiber, polypropylene, and twisted strand steel cord), various embedment lengths (17\% to $50 \%$ of the fiber length), and two water-to-binder ratios (0.4 and 0.5$)$. The specimen designations are in the order of water/binder ratio, fiber type, and embedment length. For example, 0.4C7.5 indicates that the water-to-binder ratio is 0.4 , the fiber type is carbon fiber, and the embedment length is $7.5 \mathrm{~mm}$.

Figure 2 shows the different composite fiber types, and Table 1 presents the dimensions and mechanical properties of the composite fibers.

At least three specimens were prepared for each fiber type case and water-to-binder ratio and embedment length, as shown in Table 2. All specimens were cured in water for 14 days at $40^{\circ} \mathrm{C} \pm 5^{\circ} \mathrm{C}$ until testing. A cubic mold $(50 \times$ $50 \times 50 \mathrm{~mm}$ ) was used to determine the compressive strength of the cement composites. Tables 3 and 4 show the material properties and mix proportions used in the cement composites, respectively.

This study used a typical test set-up for the single-fiber pull-out testing of the specimens. The pull-out force and slippage displacement at the ends (tips) were recorded by 
TABLE 1: Dimensions and mechanical properties of composite fibers.

\begin{tabular}{lccccc}
\hline Type & $\begin{array}{c}\text { Diameter } \\
(\mu \mathrm{m})\end{array}$ & $\begin{array}{c}\text { Fiber length, } \\
L_{f}(\mathrm{~mm})\end{array}$ & $\begin{array}{c}\text { Aspect } \\
\text { ratio }\end{array}$ & $\begin{array}{c}\text { Tensile strength } \\
(\mathrm{MPa})\end{array}$ & $\begin{array}{c}\text { Elastic modulus } \\
(\mathrm{GPa})\end{array}$ \\
\hline Carbon fiber $(\mathrm{C})$ & 7 & 6 & 857 & 3500 & 120 \\
Polypropylene $(\mathrm{P})$ & 40 & 15 & 375 & 600 & 3.7 \\
Steel cord $(\mathrm{S})$ & 405 & 32 & 79 & 2300 & 206 \\
\hline
\end{tabular}

TABLE 2: Parameters for testing.

\begin{tabular}{lcccc}
\hline Fiber type & Water/binder $(\mathrm{w} / \mathrm{b})$ & \multicolumn{2}{c}{ Embedment length, $L_{e}(\mathrm{~mm})$} & Number of specimens \\
\hline \multirow{3}{*}{ Carbon fiber (C) } & 0.4 & 1.0 & $17 \%$ of $L_{f}$ & 3 \\
& 0.5 & 1.5 & $25 \%$ of $L_{f}$ & 3 \\
\hline \multirow{3}{*}{ Polypropylene fiber (P) } & 0.4 & 3.0 & $50 \%$ of $L_{f}$ & 3 \\
& 0.5 & 3.75 & $25 \%$ of $L_{f}$ & 5 \\
& & 5.0 & $33 \%$ of $L_{f}$ & 5 \\
Steel cord (S) & 0.4 & 7.5 & $50 \%$ of $L_{f}$ & 5 \\
& 0.5 & 7.5 & $24 \%$ of $L_{f}$ & 5 \\
\hline
\end{tabular}

TABLE 3: Material properties for cement composites.

\begin{tabular}{ll}
\hline Cement & $\begin{array}{l}\text { High early strength cement, density: } 3.17 \mathrm{~g} / \mathrm{cm}^{3}, \\
\text { fineness: } 3,230 \mathrm{~cm}^{2} / \mathrm{g}\end{array}$ \\
\hline Sand & $\begin{array}{l}\text { Silica sand, density: } 2.64 \mathrm{~g} / \mathrm{cm}^{3}, \text { grade: } \\
0.1 \sim 0.3 \mathrm{~mm}\end{array}$ \\
\hline Fly-ash & Density: $2.13 \mathrm{~g} / \mathrm{cm}^{3}$, fineness: $2,976 \mathrm{~cm}^{2} / \mathrm{g}$ \\
\hline $\begin{array}{l}\text { High water- } \\
\text { reducing } \\
\text { agent }\end{array}$ & Polycarboxylate \\
\hline
\end{tabular}

a data acquisition system during the tests. The specimens were tested under increasing monotonic pull-out loading using $30-\mathrm{kN}$ capacity universal testing machine (INSTRON) with displacement control at a rate of $0.2 \mathrm{~mm} / \mathrm{min}$ until the fibers were pulled out. Figure 3 shows a schematic test set-up for the single-fiber pull-out test.

\section{Results and Discussion}

3.1. Pull-Out and Slippage Characteristics. Regardless of the fiber type, the pull-out load increased almost linearly at the beginning of the test, followed by abrupt discontinuity after reaching the peak pull-out load due to the loss of the friction-adhesive bond. Subsequently, nonlinear behavior was observed due to the reduction of the interfacial adhesion capacity between the fiber and the cement composite matrix. Figure 4(a) shows the interfacial surfaces of the cement composites after the polypropylene fiber was pulled out. The surface texture is smooth without voids, and no noticeable defects can be seen in the cement composite matrix and fibers as shown in Figures 4(b), 4(c), and 4(d).
3.2. Effect of Water-to-Binder Ratio and Embedment Length $\left(L_{e}\right)$ for Carbon Fiber. The water-to-binder ratio may affect the interfacial bond strength between the fiber and the cement composite matrix. Figures 5(a) and 5(b) present the pull-out load versus pull-out slip results for the specimens with carbon fiber. Table 5 presents a summary of the test results from this study. The initial stiffness values were computed based on the slippage distance at the load that corresponds to $30 \%$ of the peak pull-out load.

As the water-to-binder ratio increased, the peak pull-out load was not affected significantly. However, the postpeak pull-out load values for the $0.5 \mathrm{C} 1.5$ and $0.5 \mathrm{C} 1.0$ specimens dropped rapidly after reaching the peak pull-out load. The $0.5 \mathrm{C} 1.5$ and $0.5 \mathrm{C} 3.0$ specimens tended to exhibit gradually decreasing pull-out loads after reaching the peak pull-out load, and specimen $0.5 \mathrm{C} 3.0$ showed better resistance to deformation and toughness until the carbon fiber was fully pulled out. However, the initial stiffness values of the specimens with the water-to-binder ratio of 0.4 were similar to those of the corresponding specimens with a water-to-binder ratio of 0.5 .

As the embedment length of the fiber increased, the chemical bond strength also increased, whereas the frictional bond strength slightly decreased, even when the embedment length increased. These results may be due to the fact that the incremental increase in the interfacial bond surface area with the carbon fiber was compensated by the reduction in interfacial bond strength.

For the specimens with polypropylene fiber, the peak pull-out load was not affected significantly, as indicated by the increasing strength of the matrix, as seen in Figures 6(a) and 6(b). However, no sudden load drop occurred after the peak pull-out load, except for specimen 0.5P3.75. The specimens with polypropylene fiber tended to exhibit gradually increasing and decreasing pull-out loads due to 
TABLE 4: Mix proportions for cement composites.

\begin{tabular}{|c|c|c|c|c|c|c|c|}
\hline \multirow{2}{*}{ Fiber type } & \multirow{2}{*}{ w/b (wt.) } & \multirow{2}{*}{ FA/B (wt.) } & \multicolumn{4}{|c|}{ Unit weight $\left(\mathrm{kg} / \mathrm{m}^{3}\right)$} & \multirow{2}{*}{$f_{c}^{\prime}(\mathrm{MPa})$} \\
\hline & & & Cement & Water & Fly-ash & Sand & \\
\hline \multirow{2}{*}{$\mathrm{C}$} & 0.40 & 0.20 & 762 & 381 & 191 & 627 & 54 \\
\hline & 0.50 & 0.20 & 672 & 420 & 168 & 627 & 46 \\
\hline \multirow{2}{*}{$\mathrm{P}$} & 0.40 & 0.20 & 762 & 381 & 191 & 627 & 54 \\
\hline & 0.50 & 0.20 & 672 & 420 & 168 & 627 & 44 \\
\hline \multirow{2}{*}{ S } & 0.40 & 0.20 & 762 & 381 & 191 & 627 & 54 \\
\hline & 0.50 & 0.20 & 672 & 420 & 168 & 627 & 46 \\
\hline
\end{tabular}
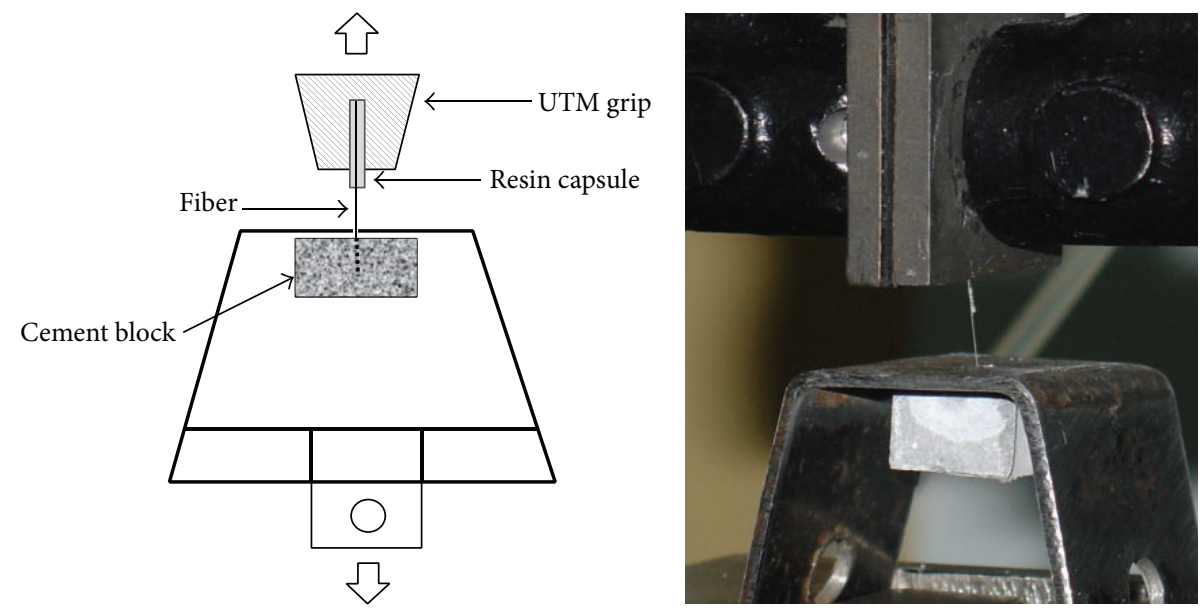

FIgURE 3: Schematic drawing for single-fiber pull-out test and photograph of test set-up.

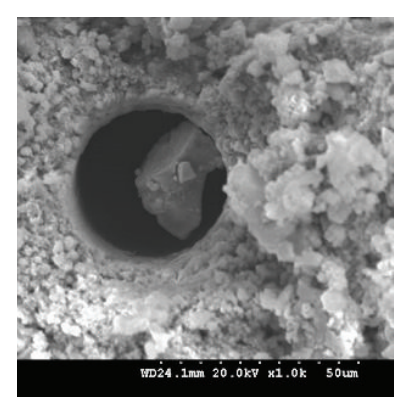

(a) Interfacial surface of the matrix

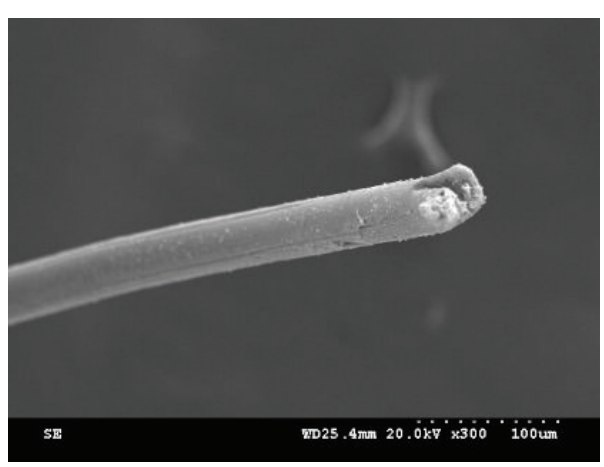

(c) Polypropylene surface

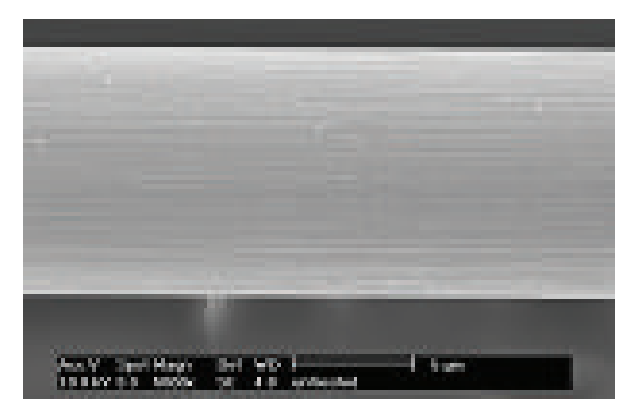

(b) Carbon fiber surface

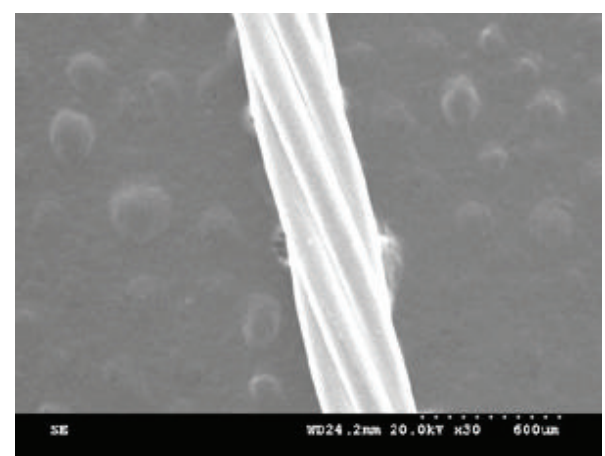

(d) Steel cord surface

FIgURE 4: Interfacial surfaces of the cement composite matrix and fiber surfaces. 
TABLE 5: Summary of test results.

\begin{tabular}{lcccc}
\hline I.D. & $\delta_{0}(\mathrm{~mm})$ & $\delta(\mathrm{mm})$ & Initial stiffness $(\mathrm{N} / \mathrm{mm})$ & Peak pull-out load $(\mathrm{N})$ \\
\hline $0.4 \mathrm{C} 3.0$ & 0.098 & 0.150 & 3.940 & 0.616 \\
$0.4 \mathrm{C} 1.5$ & 0.088 & 0.143 & 3.700 & 0.460 \\
$0.4 \mathrm{C} 1.0$ & 0.093 & 0.137 & 2.380 & 0.340 \\
$0.5 \mathrm{C} 3.0$ & 0.110 & 0.222 & 3.613 & 0.603 \\
$0.5 \mathrm{C} 1.5$ & 0.109 & 0.150 & 2.756 & 0.503 \\
$0.5 \mathrm{C} 1.0$ & 0.100 & 0.155 & 2.241 & 0.309 \\
\hline $0.4 \mathrm{P} 7.5$ & 0.276 & 1.316 & 2.252 & 0.405 \\
$0.4 \mathrm{P} 5.0$ & 0.310 & 0.918 & 0.777 & 0.306 \\
$0.4 \mathrm{P} 3.75$ & 0.277 & 1.763 & 0.870 & 0.228 \\
$0.5 \mathrm{P} 7.5$ & 0.323 & 1.288 & 2.346 & 0.374 \\
$0.5 \mathrm{P} 5.0$ & 0.386 & 0.703 & 0.711 & 0.298 \\
$0.5 \mathrm{P} 3.75$ & 0.279 & 0.443 & 1.096 & 0.199 \\
\hline 0.4 S15 & 0.226 & 0.465 & 845.1 & 207.4 \\
0.4 S7.5 & 0.302 & 0.408 & 391.6 & 171.85 \\
0.5 S15 & 0.250 & 0.552 & 510.0 & 170.44 \\
0.5 S7.5 & 0.284 & 349.3 & 135.76 \\
\hline
\end{tabular}

Note: $\delta$ is the pull-out displacement; $\delta_{0}$ corresponds to the displacement at which full debonding is completed.

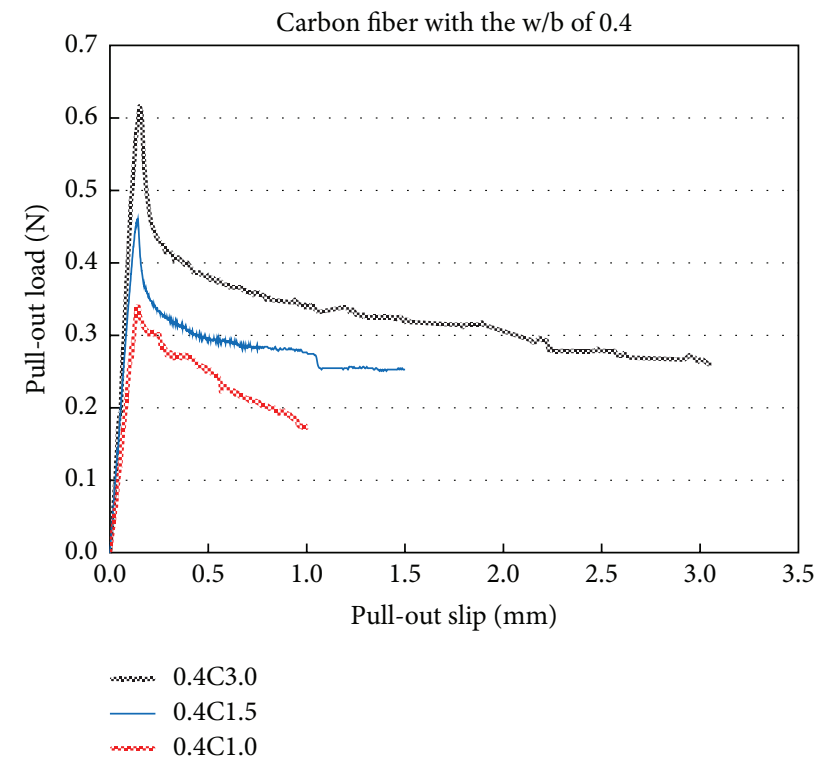

(a) Specimens with the w/b of 0.4

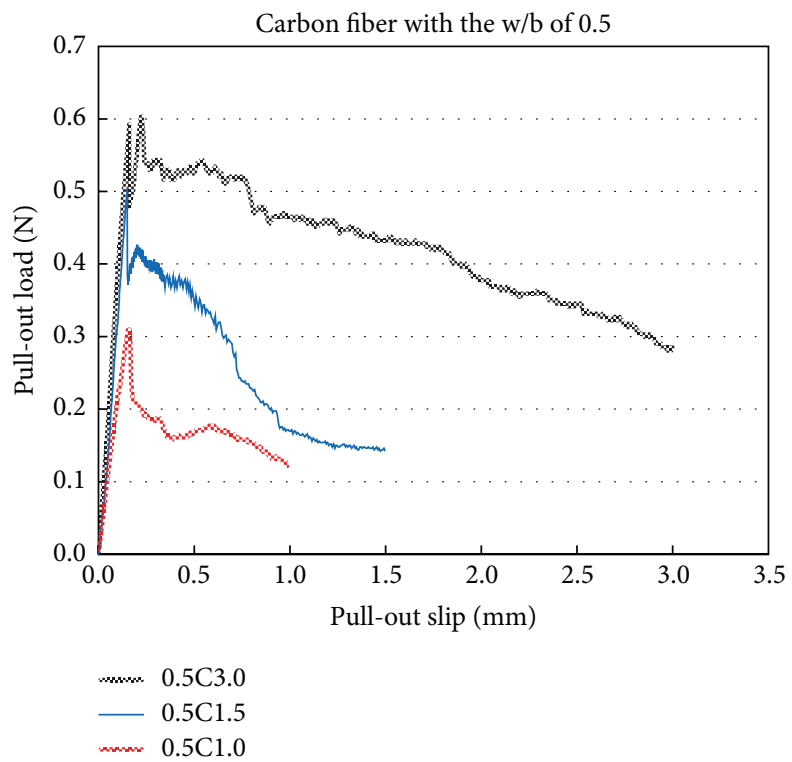

(b) Specimens with the w/b of 0.5

Figure 5: Pull-out load versus slip at the ends for specimens with carbon fiber.

the low elastic modulus value of the polypropylene fiber. For specimen 0.4 P7.5, the postpeak behavior after reaching the maximum pull-out force was maintained at a plateau, which indicates its superior resistance to deformation and toughness, although the peak pull-out load was slightly low. On the other hand, the initial stiffness and bond strength values were similar regardless of the water-to-binder ratio.

In terms of water-to-binder ratio, for the specimens with an embedment length of $7.5 \mathrm{~mm}$ with water-to-binder ratios of 0.4 and 0.5 , the maximum pull-out force increased as the water-to-binder ratio decreased. These results for the interface friction and bond strength are due to the formation of a more condensed matrix. Similar results were observed for the specimens with the embedment length of $5 \mathrm{~mm}$.

In short, a sufficient embedment length leads to mechanical bond strength and fiber plastic deformation. With a decrease in the embedment length, the maximum pull-out force is reduced.

Strain softening also was observed in this study. In general, the pull-out load increased as the embedment length increased for all three fibers regardless of the waterto-binder ratio. In particular, the pull-out response for 


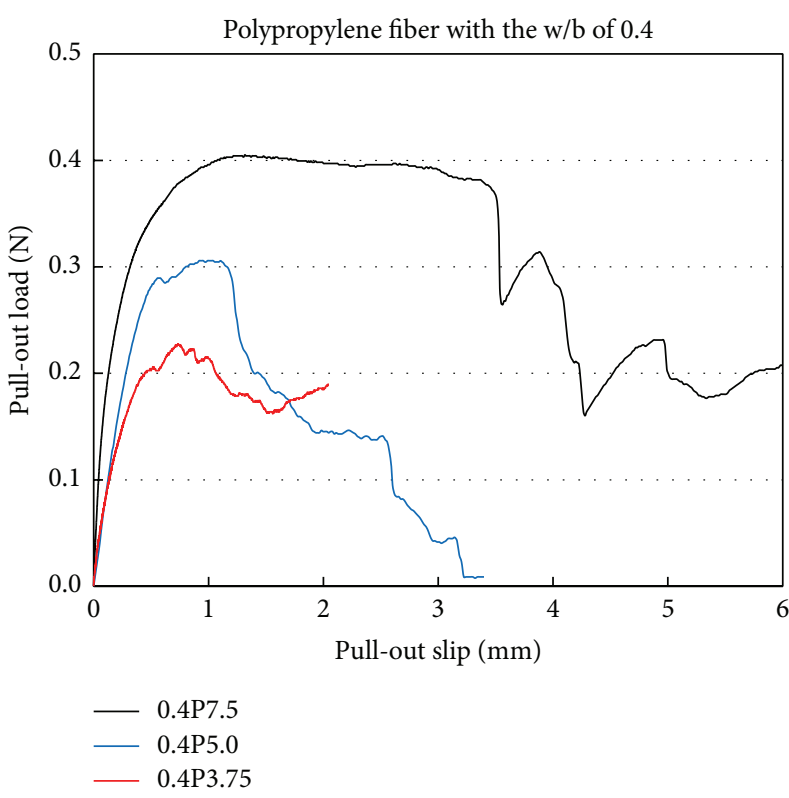

(a) Specimens with the $w / b$ of 0.4

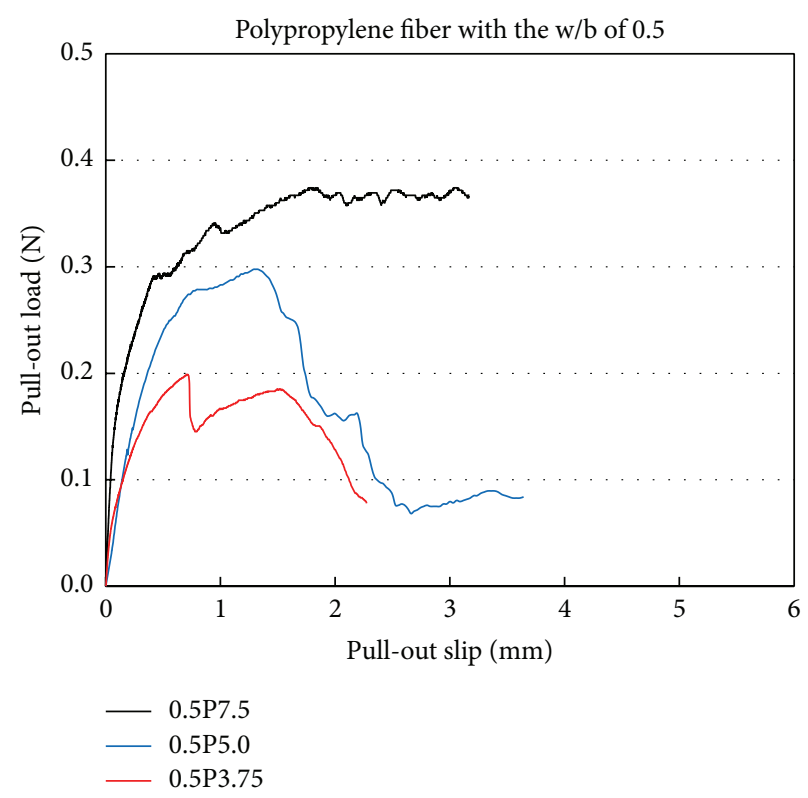

(b) Specimens with the w/b of 0.5

FIGURE 6: Pull-out load versus slip at the end for specimens with polypropylene fiber.

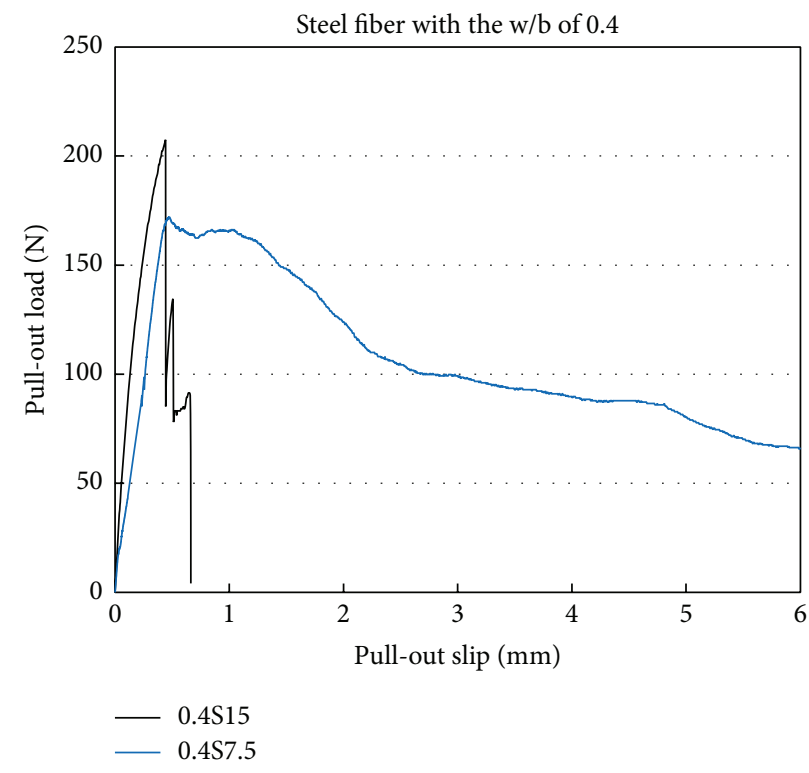

(a) Specimens with the w/b of 0.4

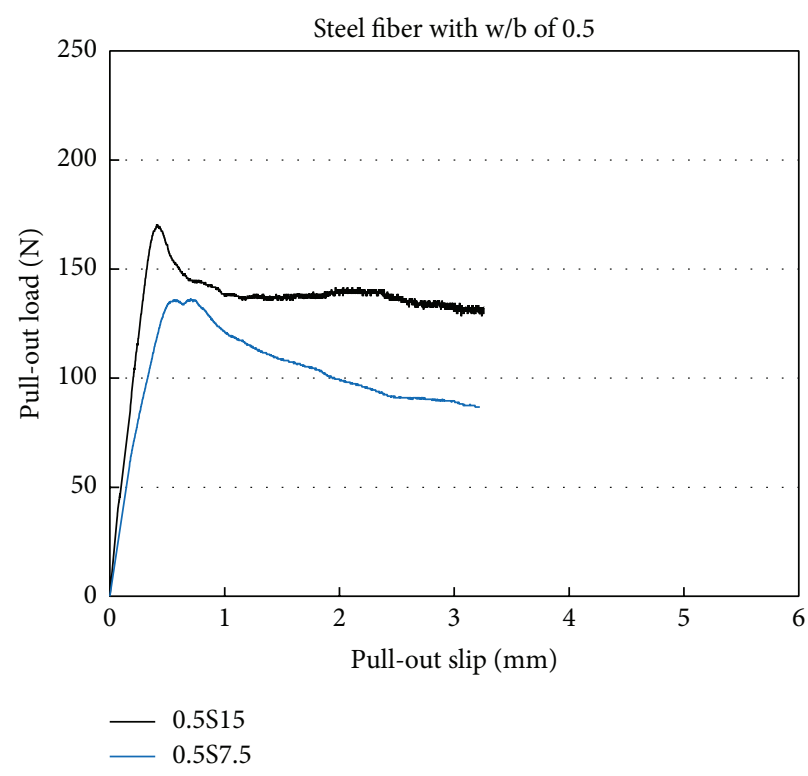

(b) Specimens with the w/b of 0.5

FIgure 7: Pull-out load versus slip at the end for specimens with steel fiber.

the specimen with polypropylene fiber with $7.5 \mathrm{~mm}$ embedment length exhibited slip-hardening behavior without any surface treatment of the fibers.

For the specimens with steel fiber, Figures $7(a)$ and 7(b) show that the pull-out load increased linearly up to the peak pull-out load. The initial stiffness value of specimen $0.4 \mathrm{~S} 15$ is high in comparison to the other specimens in that the fiber completely debonded without ductility. The slippage dropped rapidly after reaching the peak pull-out load due to the failure of the fire breakage. For the remaining specimens, the pullout force decreased gradually with slippage hardening effects.

Similarly, a sufficient embedment length was shown to enhance the mechanical bond strength and the fiber plastic deformation. As the embedment length deceased, the peak pull-out load also decreased. On the other hand, tensile rupture failure was observed for specimen $0.4 \mathrm{~S} 15$ with steel fiber. Therefore, a shorter embedment length indicates expected slip-hardening effects for ductile behavior. 


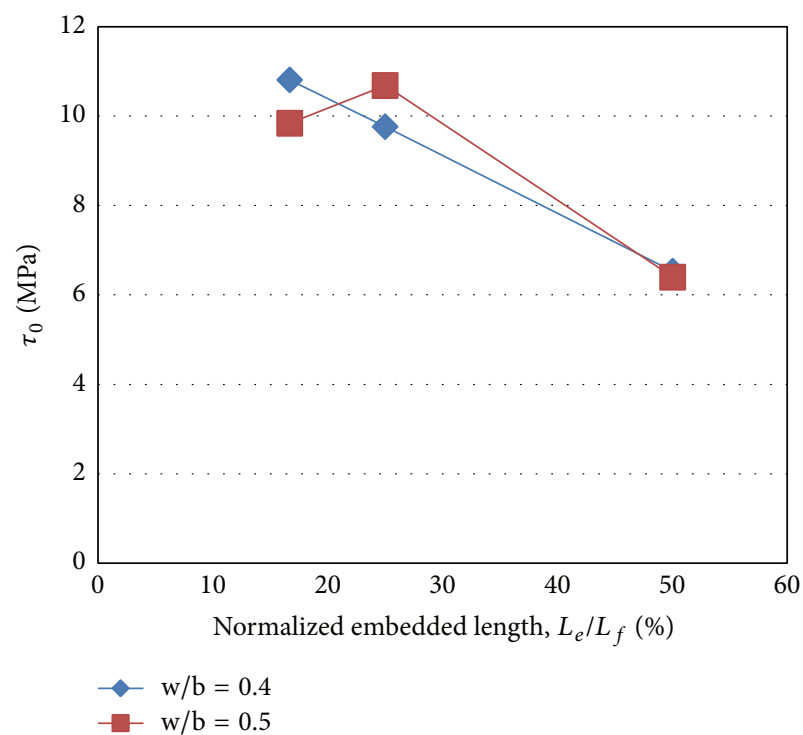

(a) Carbon fiber

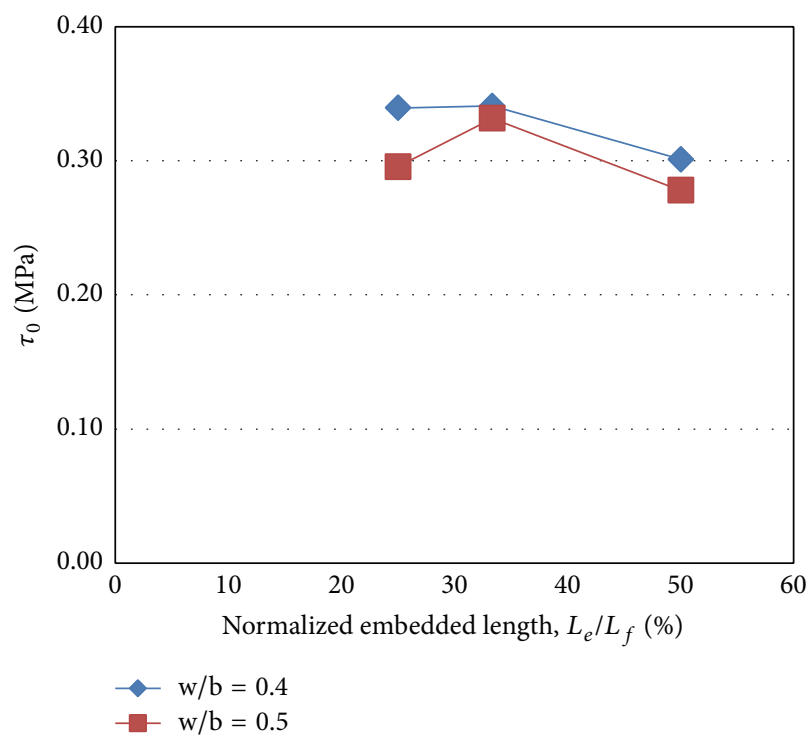

(b) Polypropylene fiber

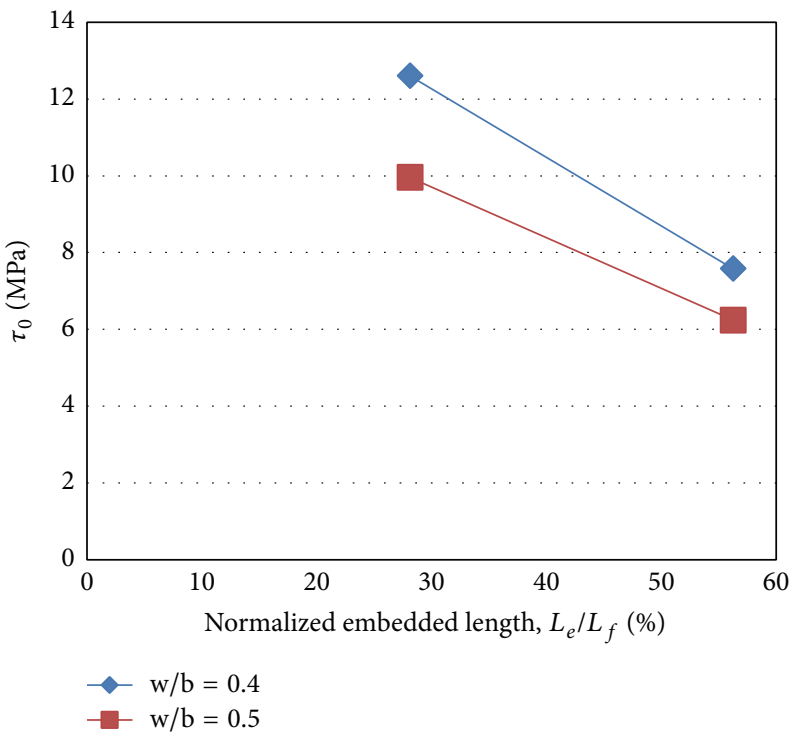

(c) Steel cords

FIGURE 8: Frictional bond stress $\left(\tau_{0}\right)$ with respect to normalized embedment length $\left(L_{e} / L_{f}\right)$.

\section{Numerical Methods to Determine Interface Properties}

Three typical descending behaviors were observed after the peak pull-out load: slip softening, constant friction, and slip-hardening in the fiber slippage phase [10]. Two numerical models can be found in the literature regarding these phenomena: a strength-controlled model and a fracture-controlled model. The fracture-controlled model that is adopted in this study is known to be capable of predicting fiber slippage. According to the literature $[4,11]$, because relative slippage between the fiber and the matrix in the debonded portion is limited to a small area, the initial friction bond stress $\left(\tau_{0}\right)$ within the debonded zone remains at a constant so that the initial frictional bond stress can be expressed as

$$
\tau_{0}=\frac{P_{b}}{\pi d_{f} L_{e}}
$$

where $P_{b}$ is the load after the sudden drop following the peak pull-out load (70\% of $\left.P_{a}\right) ; L_{e}$ is the fiber embedment length; and $d_{f}$ is the diameter of the fiber. 


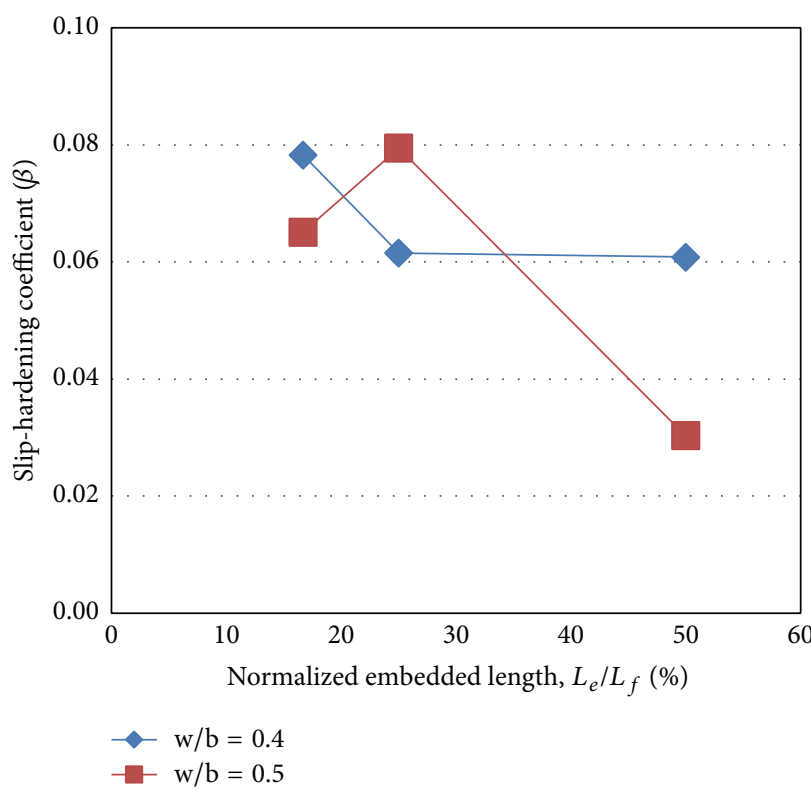

(a) Carbon fiber

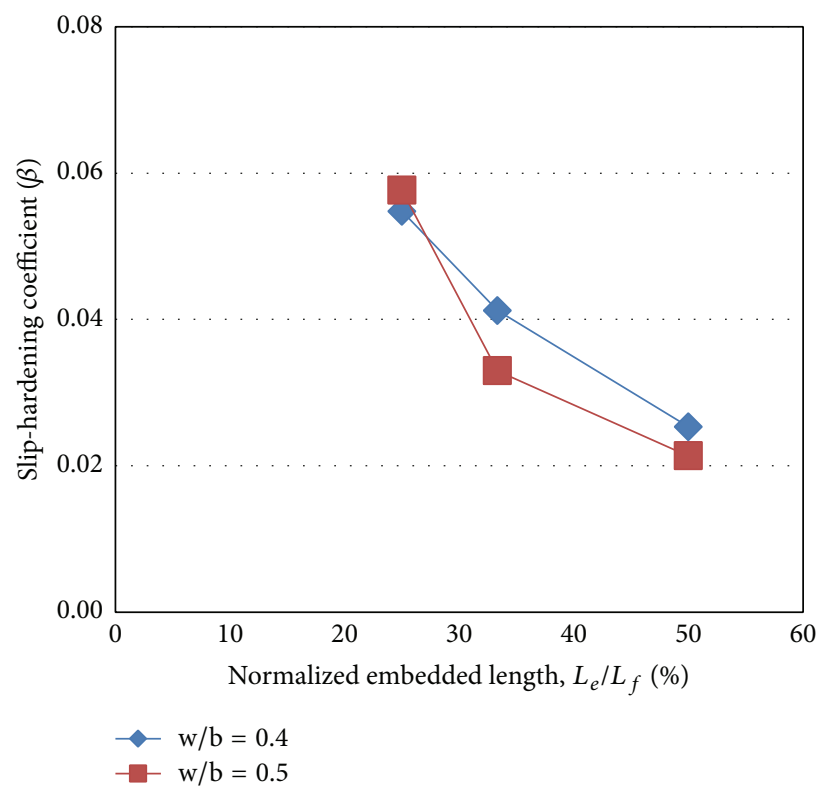

(b) Polypropylene fiber

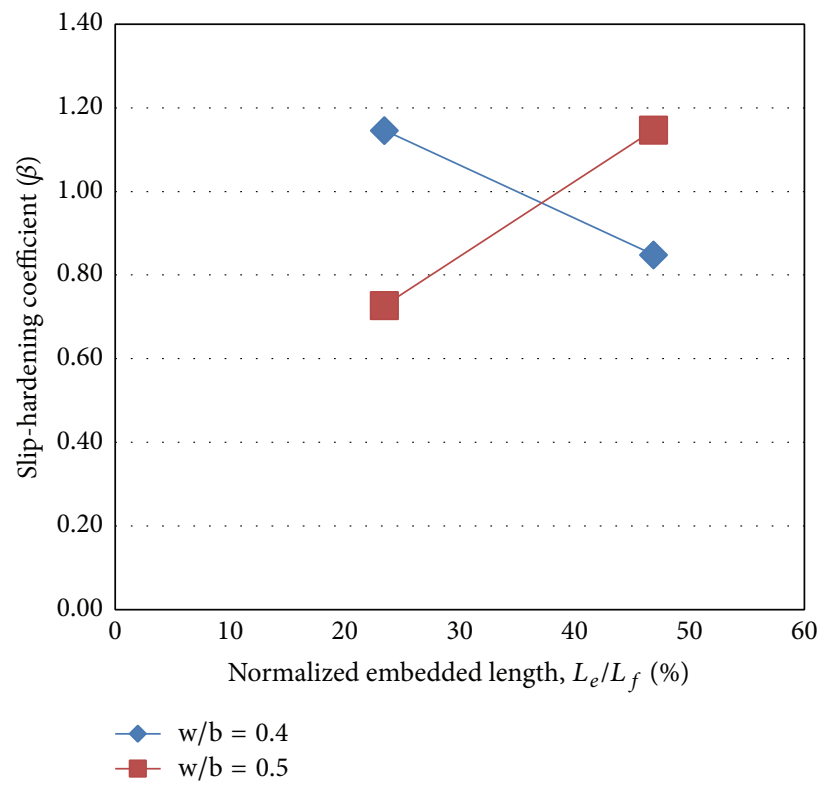

(c) Steel cords

FIGURE 9: Slip-hardening coefficient $(\beta)$ with respect to normalized embedment length $\left(L_{e} / L_{f}\right)$.

After reaching the peak pull-out load $\left(P_{a}\right)$, the interface shear stress cannot be determined solely using the friction stress that results from the pulling-out process of the fiber. So, the interface shear stress can be expressed using the sliphardening coefficient $(\beta)$ and slip distance $(S)$ :

$$
\tau=\tau_{0}\left(1+\frac{\beta S}{d_{f}}\right)
$$

The relationship between theoretical pull-out load $P$ and pullout slip $\delta$ can be expressed by [11]:

$P$

$$
=\left[\begin{array}{cc}
\sqrt{\frac{\pi^{2} \tau_{0} E_{f} d_{f}^{3}(1+\eta)}{2} \delta+\frac{\pi G_{d} E_{f} d_{f}^{3}}{2}}, & 0 \leq \delta \leq \delta_{0}, \\
\pi d_{f} \tau_{0}\left(1+\frac{\beta\left(\delta-\delta_{0}\right)}{d_{f}}\right)\left(L_{e}-\delta+\delta_{0}\right), & \delta_{0} \leq \delta \leq L_{e},
\end{array}\right.
$$




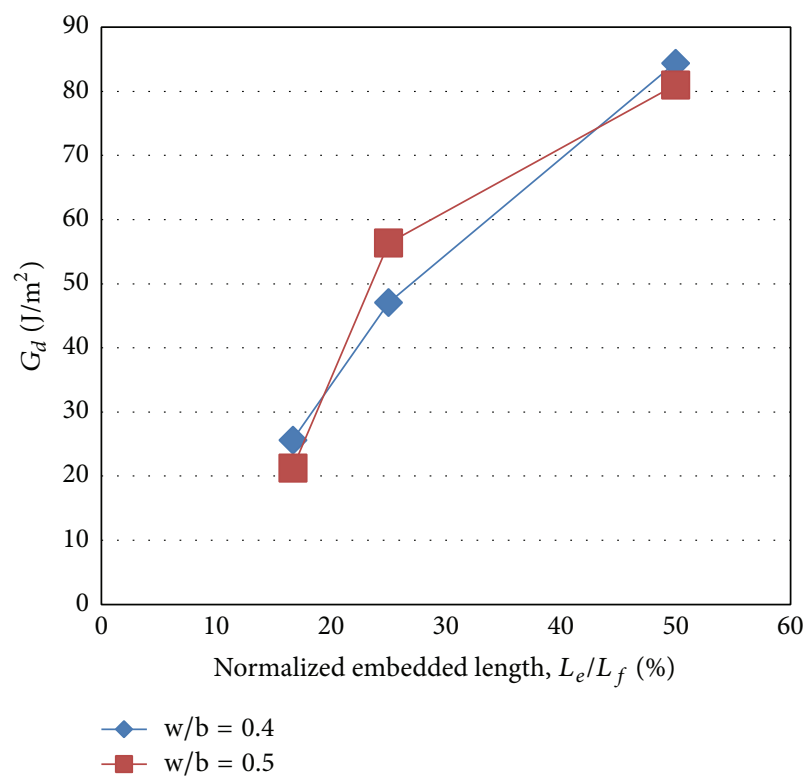

(a) Carbon fiber

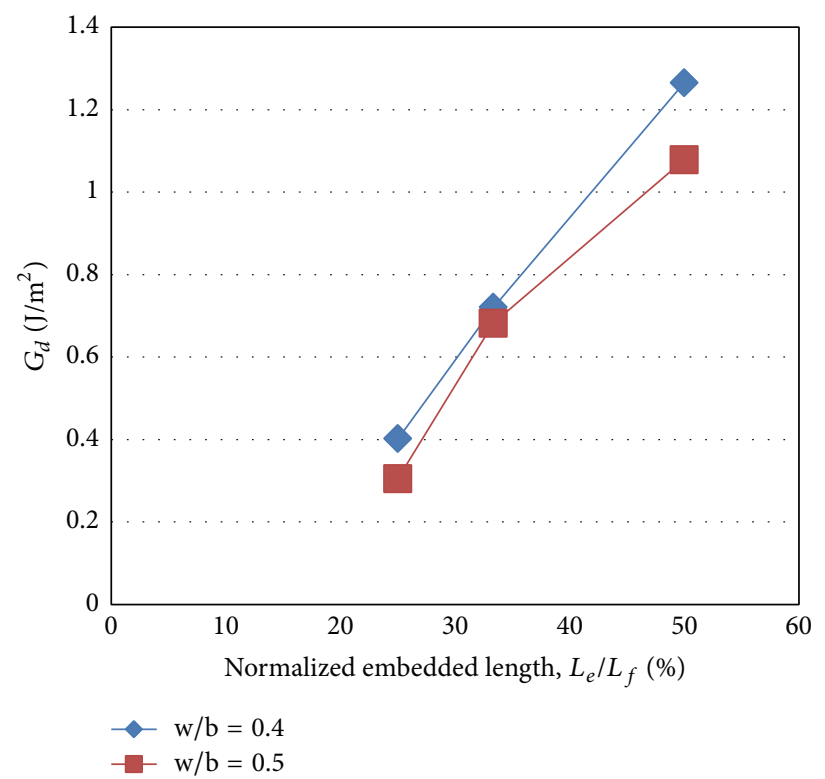

(b) Polypropylene fiber

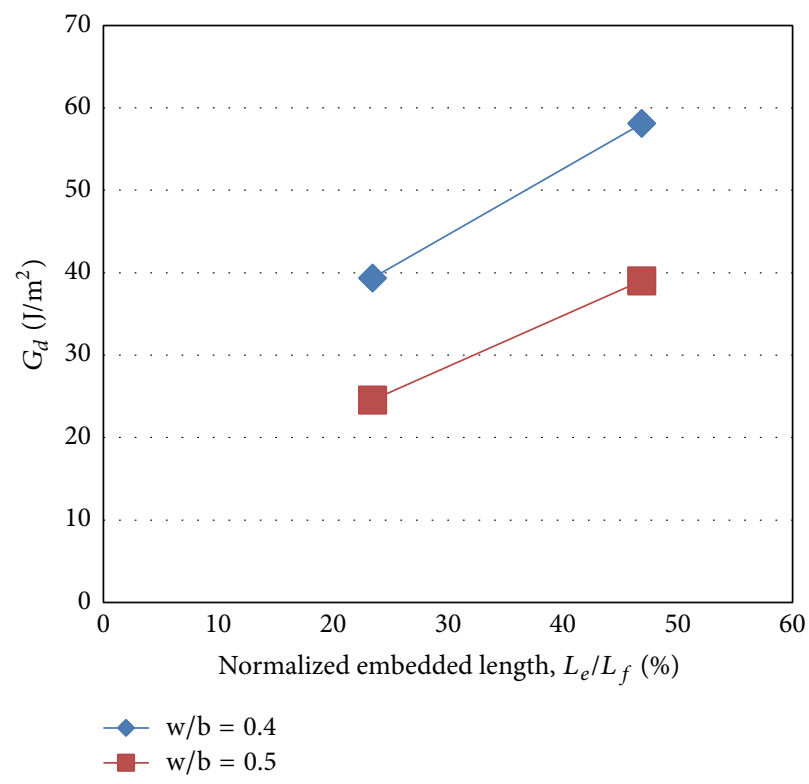

(c) Steel cords

FIgURE 10: Chemical bond stress $\left(G_{d}\right)$ with respect to normalized embedment length $\left(L_{e} / L_{f}\right)$.

where $\delta$ is the pull-out displacement; $\delta_{0}$ corresponds to the displacement at which full debonding is completed; $G_{d}$ is the chemical bond strength $\left(\mathrm{J} / \mathrm{m}^{2}\right) ; E_{f}$ is the elastic modulus of the fiber; $\eta=V_{f} E_{f} / V_{m} E_{m}, E_{m}$ is the elastic modulus of the matrix; and $V_{f}$ and $V_{m}$ are the volume fractions of the fiber and matrix, respectively. $\eta$ can be neglected in a single-fiber pull-out test.

These predictive equations have been validated in the literature [11] and adopted here to develop design parameters for various fibers associated with embedment length and water/binder ratio. The test results for each specimen were used in this study to calculate the interfacial bond stress, sliphardening coefficient $(\beta)$, and chemical bond strength $\left(G_{d}\right)$. $G_{d}$ value implies the interfacial fracture energy and can be computed by

$$
G_{d}=\frac{2\left(P_{a}-P_{b}\right)^{2}}{\pi^{2} E_{f} d_{f}^{3}}
$$

This fracture energy indicates the energy that is absorbed by the bridging action of the fibers over the cracked plane. It can be used to determine the optimal fiber length. The chemical 
bond stress tends to reduce the fracture energy because it leads to the rupture of the fiber.

The adopted model in this study allows the interface properties of fibers, such as carbon fiber, polypropylene fiber, and steel cord fiber, to be expressed quantitatively. Figure 8 indicates that low frictional bond stress levels $\left(\tau_{0}\right)$ were observed as the water-to-binder ratio increased, thereby resulting in a low elastic modulus value for mixtures with a high water-to-binder ratio. Moreover, the increasing porosity of the cement composite mixture in the interfacial zone that occurs as the water-to-binder ratio increases leads to a reduction of the fiber-matrix contact surface, which may result in lower frictional bond stress. Furthermore, in this study, low frictional bond stress $\left(\tau_{0}\right)$ was observed as the embedment length increased, which resulted in the lower elastic modulus value of the mixtures with a high water-tobinder ratio.

The slip-hardening coefficients $(\beta)$ presented in Figure 9 were computed by best-fitting the curve for each specimen, as shown in Figures 5-7. For the polypropylene fiber, $\beta$ values are in the range of 0.005 to 0.05 based on the literature and 0.02 to 0.06 based on this study. For the steel fiber, $\beta$ value is around 1 from the literature and in the range of 0.65 to 1.18 from this study. The study results for both fibers match well with those found in the literature [12].

Figure 10 shows the chemical bond stress $\left(G_{d}\right)$ results versus the normalized embedment lengths. For a short fiber with a low aspect ratio, the literature indicates that the pullout force is controlled by the initial debonding stress, which is consequently governed by the chemical bond. For a specimen with steel fiber with a low aspect ratio (79 for the steel fiber), as the chemical bond strength increases, the pull-out load increases noticeably, as shown in Figure 10(c).

As the fiber lengthens, the subsequent pull-out process after the initial debonding process results in an active bridging action and stronger pull-out force. The pull-out force becomes almost independent of the fiber length when the fiber is excessively long and/or the chemical bond is excessively strong [11].

\section{Conclusion}

This research was undertaken to establish a design methodology for composites using single-fiber pull-out tests. For this purpose, the study presents the characteristics of both fibermatrix interfacial properties and fiber rupture. The results of these tests allow specific design parameters to be evaluated quantitatively:

(1) As the compressive strength of the cement composite and the embedment length of a single fiber increased incrementally, the pull-out force also increased.

(2) The slip-hardening coefficients $(\beta)$ for specimens with steel fiber ranged from 0.65 to 1.18 in this study. For specimens with polypropylene fiber, $\beta$ value was in the range of 0.02 to 0.06 . These results match well with the results found in the literature. In the same manner, $\beta$ value for the carbon fiber was in the range of 0.03 to 0.08 .
(3) The chemical bond strength was relatively stable and was independent of the water-to-binder ratio of the matrix and fiber that had a high aspect ratio, which is contrary to the behavior that was resultant of the friction bond strength. The fracture-controlled theory adopted here was found to be capable of reasonably interpreting and reproducing the singlefiber pull-out test data.

\section{Conflict of Interests}

The authors declare that there is no conflict of interests regarding the publication of this paper.

\section{Acknowledgment}

The work reported here was financially supported by Gachon University research fund of 2014 (GCU-2014-0105).

\section{References}

[1] J. M. Alwan, A. E. Naaman, and W. Hansen, "Pull-out work of steel fibers from cementitious composites: analytical investigation," Cement and Concrete Composites, vol. 13, no. 4, pp. 247255, 1991.

[2] V. C. Li, H. C. Wu, and Y. W. Chan, "Interface property tailoring for pseudo strain-hardening cementitious composites," in Advanced Technology for Design and Fabrication of Composite Materials and Structures, vol. 14 of Engineering Applications of Fracture Mechanics, pp. 261-268, Springer, Amsterdam, The Netherlands, 1995.

[3] V. C. Li and H. Stang, "Interface property characterization and strengthening mechanisms in fiber reinforced cement based composites," Advanced Cement Based Materials, vol. 6, no. 1, pp. $1-20,1997$.

[4] T. Kanda and V. C. Li, "Interface property and apparent strength of high-strength hydrophilic fiber in cement matrix," Journal of Materials in Civil Engineering, vol. 10, no. 1, pp. 5-13, 1998.

[5] V. M. C. F. Cunha, J. A. O. Barros, and J. M. Sena-Cruz, "Pullout behavior of hooked-end steel fibres in self-compacting concrete," Journal of Materials in Civil Engineering, vol. 22, no. 1, pp. 1-9, 2010.

[6] Y. Lee, S.-T. Kang, and J.-K. Kim, "Pullout behavior of inclined steel fiber in an ultra-high strength cementitious matrix," Construction \& Building Materials, vol. 24, no. 10, pp. 20302041, 2010.

[7] P. Di Maida, E. Radi, C. Sciancalepore, and F. Bondioli, "Pullout behavior of polypropylene macro-synthetic fibers treated with nano-silica," Construction and Building Materials, vol. 82, pp. 39-44, 2015.

[8] Y.-W. Chan and S.-H. Chu, "Effect of silica fume on steel fiber bond characteristics in reactive powder concrete," Cement and Concrete Research, vol. 34, no. 7, pp. 1167-1172, 2004.

[9] H. D. Yun, E. Jeon, W. S. Park, B. C. Han, I. S. Yang, and Y. S. Lee, "Pull-out response and surface treatment of carbon fiber with fluorination," Journal of the Architectural Institute of Korea Structure \& Construction, vol. 21, no. 8, pp. 27-34, 2005 (Korean). 
[10] T. Nakajima, Fluorine-Carbon and Fluoride-Carbon Materials, CRC Press, 1995.

[11] Z. Lin, T. Kanda, and V. C. Li, "On Interface property characterization and performance of fiber-reinforced cementitious composites," Journal of Concrete Science and Engineering, vol. 1, pp. 173-184, 1999.

[12] F. Aslani and S. Nejadi, "Bond characteristics of steel fibre reinforced self-compacting concrete," Canadian Journal of Civil Engineering, vol. 39, no. 7, pp. 834-848, 2012. 

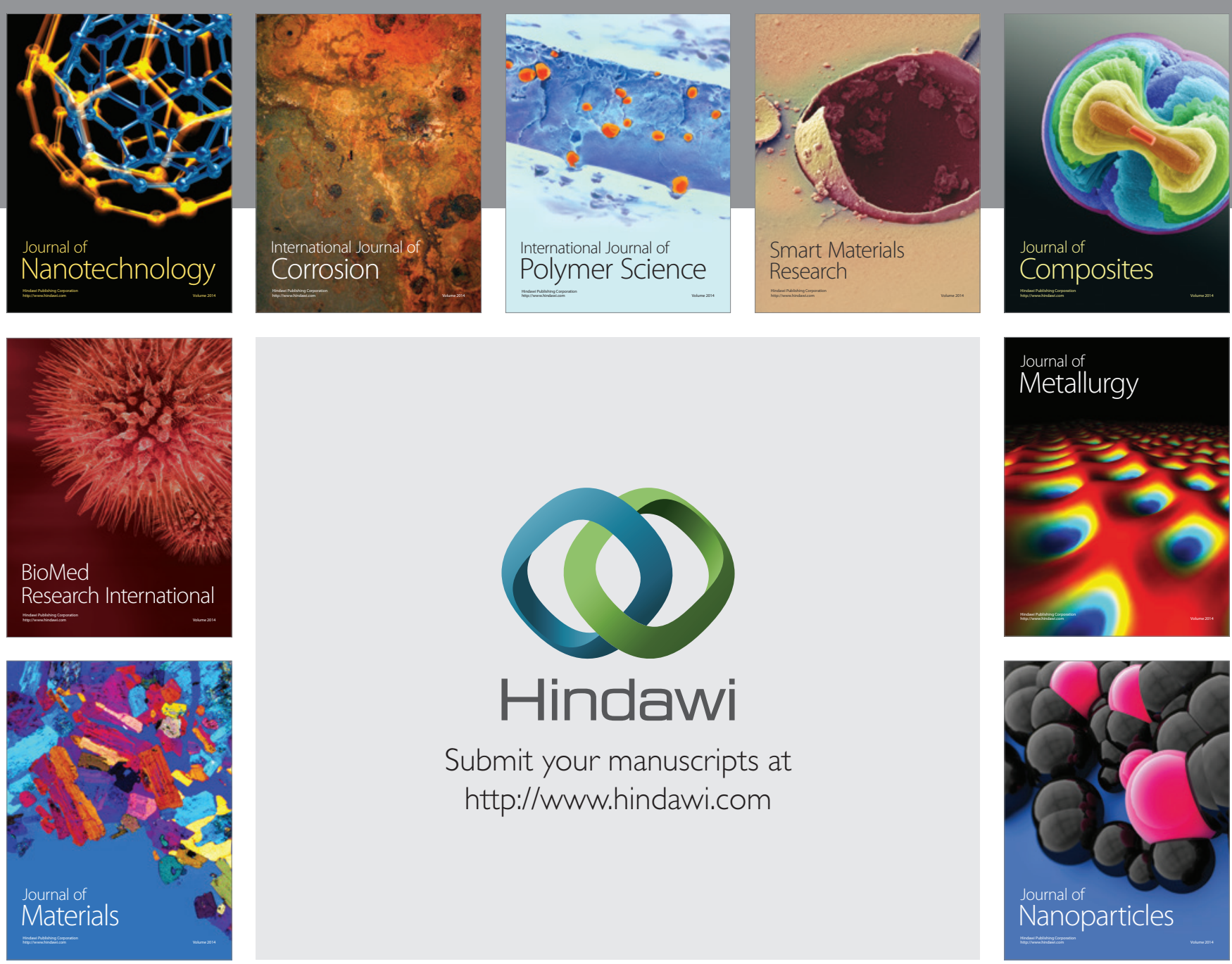

Submit your manuscripts at http://www.hindawi.com
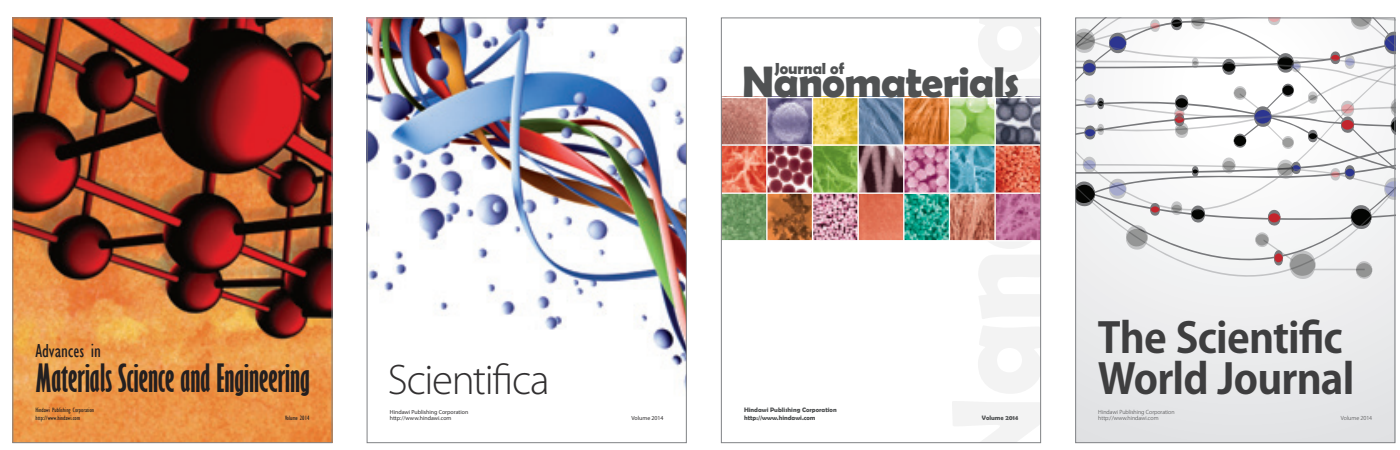

\section{The Scientific World Journal}
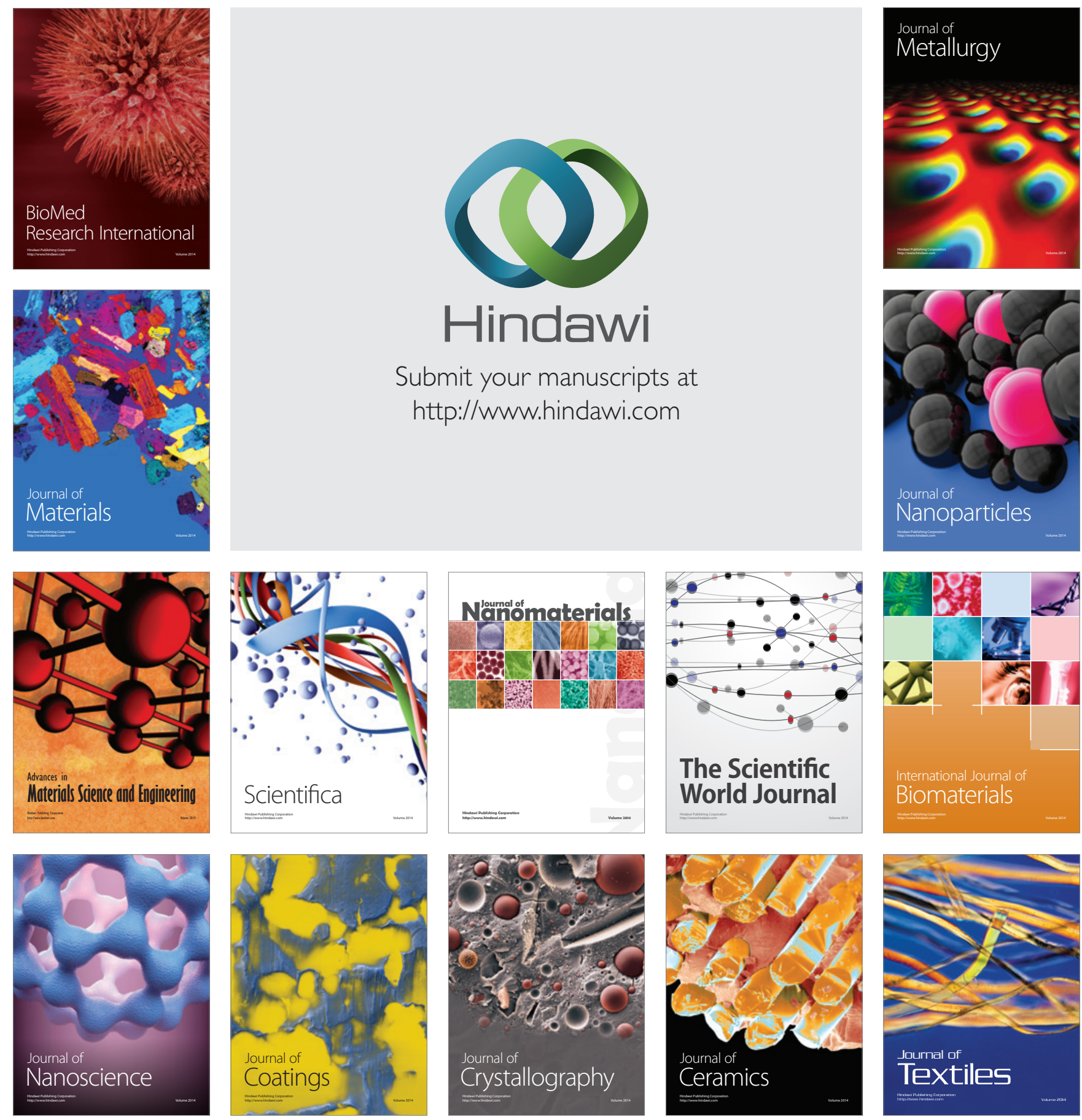